\title{
Otto Neurath: Marxist Member of the Vienna Circle
}

\author{
DR. STRUAN JACOBS \\ Deakin University
}

\section{KARL-HEINZ OTTO}

Australia

\section{Introduction}

The Vienna Circle is generally regarded as an apolitical group. Its members are depicted as preoccupied with the logical analysis of scientific knowledge, dismissing value-laden questions of politics as outside their area of competence. But one notable figure - Otto Neurath (1882-1945) certainly belies this view. The difference between Neurath and other members of the Vienna Circle is sharply etched by Rudolf Carnap:

\begin{abstract}
All of us in the Circle were strongly interested in social and political progress. Most of us, myself included, were socialists. But we liked to keep our philosophical work separated from our political aims. In our view, logic, including applied logic, and the theory of knowledge, the analysis of language, and the methodology of science, are, like science itself, neutral with respect to practical aims ... for a society. Neurath criticized strongly this neutralist attitude, which in his opinion gave aid and comfort to the enemies of social progress. 1
\end{abstract}

One of the few members of the Vienna Circle with extensive training and professional interest in social disciplines, Neurath formed a commitment to Marxism in the First World War, a comparatively undogmatic commitment expressing his view that theories are programmes to be developed through constant reappraisal.

Attention in this paper will be focused on relations between Neurath's Marxism and his metascience, as expressed in his writings during the career of the Vienna Circle (circa 1925-1933).

- The authors are grateful to anonymous readers of the journal for several helpful suggestions.

${ }^{1}$ Rudolf Carnap, "Carnap's Intellectual Autobiography," the Philosophy of Rudolf Carnup, ed. Paul Arthur Schilpp (La Salle, Illinois: Open Court, 1963), p. 23. Emphasis added. 
Neurath's Historical Framework

Ncurath's ideas on science and politics are set in a broad historical perspective, elements of which owe to Marx and Engels' materialist conception of history (as will become apparent below), and which is possibly influenced by the account of cultural evolution in J. G. Frazer's The Golden Bough. ${ }^{2}$

In The Golden Bough the course of human culture is described as a scquence of magical, religious and scientific 'ages.' Frazer (in the second and following cditions of the work) contrasts magic against religion, and describes magic as 'identical' to science in respect of being based on belief in 'the order and uniformity of nature. ${ }^{3}$

Neurath, for his part, looks on magic, religion and science not as distinguishable ages but as types of thought. Rather than being separated hy breaks or ruptures, these modes long coexist and form complex rclations with onc another. Magic and science are bracketed by Neurath as empirical in character and predictive in purpose, and he cites a number of specific substantive similarities. For instance, in the primitive conception, a corpse is often taboo; whoever touches it brings death upon himself. (Modern analogy: infection.) Or: disease is removed by incisions, taltooings, into the body. (Analogy: bleeding, operations.) ${ }^{4}$ The principal difference lies in science attaining a higher degree of systematic control by experience.

Where magicians claimed powers over nature, Christianity effectively abnegated these powers by attributing every event to God's will, which 'closed outlook' Neurath dismisses as unverifiable and meaningless. Religious thinking extends into philosophy. Theologians have allies in metaphysicians and moral philosophers, particularly idealist philosophers in the tradition of Kant. Opposed to theologians and their philosophical allies are 'adherents of a scientific view of the world, recognizing no authority other than science. For them the task is to make predictions

${ }^{2}$ The evidence for possible influence consists in their typology of thought as religious, magical and scientific, and in Neurath's sharing Frazer's view that magic displays substantive similarities, both broad and specific, with science. For approving references to Frazer see: Otto Neurath, Philosophical Papers 1913-1946, eds. and trans. Robert S. Cohen and Marie Neurath (Dordrecht: Reidel, 1983) p. 33; and Otto Neurath, Empiricism and Sociolngy, eds. Marie Neurath and Robert S. Cohen, trans. Paul Foulkes and Maric Neurath (Dordrecht: Reidel, 1973) p. 321.

3J. G. Frazcr, The Golden Bough, 3rd ed., part 1, vol. 1 (London: Macmillan, 1911) p. 220, also $x x$.

${ }^{4}$ Neurath, Papers , p. 34. 


\section{OTTO NEURATH}

about testable states of affairs. ${ }^{5}$ In Neurath's essentially pragmatic conception of science, prediction is stressed rather than classification and explanation. Since the Renaissance, the scientific mode of thought has, he believes, gradually developed alongside religion and metaphysics. Physics has come to be purged of metaphysical doctrines (e.g. absolute space and absolute motion), and the time Neurath now sces as ripe for social science to undergo similar cleansing.

In Anti-Duhring, Engels described contradiction as the 'main lever of all intellectual advance, 6 and Neurath as well is keenly aware of contradictions in cultural developments. Religious thinkers have contributed to science and unwittingly undermined Christian thought. Logic and mathematics have been advanced by theologians, mathematical astronomy benefited from Kepler's search for divine harmony in the universe, the conservative Catholic, Duhem, has advanced understanding of science. German idealists, for their part, unwittingly contributed to the rise of Marx and Engels' doctrine of historical materialism, which lies at the centre of Neurath's perspective. Although mindful that relations between its categories of economic base and superstructure (state, culture and social consciousness) remain to be accurately defined and explained, Neurath's assessment of historical materialism is not seriously impaired by this for he commends it as a genuincly scientific view.

Neurath affirms the Marxist order of feudal, capitalist, and socialist phases of economic-political development, and indicates that they overlap with the three modes of thought above. Theological thinking, for instance, dominated the feudal order and has remained ascendant in the capitalist period to date. But science and technology are gaining in popularity and come into increasing conflict with theological thinking, reflecting the mechanization of the process of production and the polarization of social classes. To defend its power and privileges the bourgeoisie has entered a conservative alliance with clerical groups, while the proletariat is attracted to unified science which under socialism, Neurath predicts, will become the ascendant mode of thought. In the 1920s and 30s, he believed, Christian theology and idealist metaphysics were being reasserted in a last desperate attempt to stem the rising tide of science and Marxist socialism.

\section{Marxism and Physicalism}

Neurath's account of science is set within the foregoing perspective on history. In clarifying science, he sees himself contributing to the future

${ }^{5}$ Neurath, Empiricism, p. 325.

6Frederick Engels, Anti-Duhring, 2nd ed. (Moscow: Foreign Languages Publishing, 1959), p. 57, also 39. 
sncialist culture. At the heart of his metascience is 'physicalism,' an attempt at reformulating materialist ontology as a semantic thesis. Can we say that Neurath's political commitment to Marxism is influential here, that his metascience and, in particular, physicalism, are an outgrowth of the matcrialist conception of history? Neurath himself may have believed this, for he says that over 'the last hundred years, materialism was usually connected with progressive ideas in political and social matters, while idealism was associated with reactionary attitudes. ${ }^{7}$ But in fact, Marx's application of the term 'materialism' to human affairs and history carries not the strict philosophical connotation of 'real' being equated with 'matcrial' but is an ascription of explanatory primacy to production and property relations. We do well to heed, and will quote in full, these cautionary words of John Plamenatz:

I doubt whether it is possible to elicit from his [Marx's] writings any coherent version of materialism. This does not mean that we can ascribe no definite opinions to him. We can say, for example, that he was not the kind of materialist who holds that mental activitics can be reduced to bodily movements and to motions in the brain, or can be treated as mere effects of them. There is virtually nothing in his writings to suggest that he held this view, and a great deal to suggest that he did not. 8

Nor to the best of our knowledge, are there unequivocal affirmations of philosophical, as distinct from historical, materialism in the works of Engcls.

Neurath's physicalism makes the meaning of a statement a function of its having referents located in space and time. Only one language is meaningful in Neurath's view, the objective or inter-subjective physicalist language. Another key element in Neurath's theory of science is one which in this paper will be designated 'linguistic closure.' This doctrine has three clements: knowledge can only be expressed in statements; statements are only comparable with one another; statements can never be appraised in terms of (compared with) 'reality,' things or experiences. 9 Linguistic closure markedly contrasts a position such as Wittgenstein's in

\footnotetext{
7 Neurath, Empiricism, p. 44.

8john Plamenatz, Karl Marx's Theory of Man (Oxford: Clarendon Press, 1975), p. 17.

${ }^{9}$ Elisabeth Nemeth, Otto Neurath und der Wiener Kreis (Frankfurt: Campus Verlag, 1981), p. 133. This facet of Neurath's thought interestingly presages a central them of Nelson Goodman's Ways of Worldmaking (Hassocks: Harvester, 1978), p. 4.
} 


\section{OTTO NEURATH}

the Tractatus, where he states that 'Reality is compared with propositions' (4.05) and 'A proposition can be true or false only in virtue of being a picture of reality' (4.06). ${ }^{10}$

Neurath's doctrines of physicalism and linguistic closure represent a via media between two epistemologies prominent at the time: the subjectivism of Ernst Mach, and Lenin's naive realism. In the late 20s, when Neurath was fashioning his own distinctive positivism, Lenin's defence of realism in his Materialism and Empirio-Criticism (1909) was official doctrine in the USSR and cononical for many Marxists in the West. Neurath was aware of this work, occasionally referring to it, but never delving into it in depth. The bulk of the work expounds and attacks the empirio-critics, Mach and Richard Avenarius; and the likes of Bogdanov, Bazarov, and Lunarcharsky, whose Machian interpretations of Marxism were spurned by Lenin as heretical.

The gist of empirio-criticism is well conveyed in these words of Mach: 'Nature is composed of sensations as its elements.... Properly speaking the world is not composed of "things" as its elements, but of colors, tones, pressures, spaces, times, in short what we ordinarily call individual sensations. 11

In opposition to the pheonomenalism that he ascribed to Mach, Lenin affirmed matter as the only reality. He coupled this with the naive realist conviction that objective reality is presented to us directly in experience and provides our standard for assessing knowledge-claims. ${ }^{12}$ For Lenin and the Bolsheviks, empirio-criticism amounted to a denial that 'science could know anything about the objective world' and with this, it was said,

10 Ludwig Wittgenstein, Tractatus Logico-Philosophicus, trans. D. F. Pears and B. F. McGuinness, 2nd ed. (London: Routledge, 1974).

${ }^{11}$ Ernst Mach, The Science of Mechanics, trans. Thomas McCormack, 6th ed. (Lasalle: Open Court, 1960), p. 579; cf. Ernst Mach, The Anulysis of Sensations, trans. C. M. Williams and Sydney Waterlow, 5th ed. (New York: Dover, 1959), p. 29ff.

12 See for example: V. I. Lenin, Materialism and Empirio-Criticism: Critical Comments on a Reactionary Philosophy (Moscow: Forcign Languages Publishing, 1947), pp. 33, 44, 48, 69, 83, 102, 126-127.

In contrast to Lenin's outright hostility, Neurath's attitude to Avenarius and Mach was one of discriminating ambivalence. While abjuring their phenomenalism, Neurath was unquestionably influenced by Mach's advocacy of the unity of science and of a unitary scientific language and, more perhaps than any other member of the Vienna Circle, he drew inspiration form Mach's anti-metaphysical stance. 
the door is opened 'to other ways of finding the truth, particularly to the ways of traditional religion. 13

Although he seems at no stage in his philosophical career to have accepted naive realism as tenable, and while such realism is plainly incompatible with his thesis of linguistic closure, Neurath felt no temptation to doubt the existence of the material world. His preferred position of physicalism reformulates materialism, with denizens of the space-time order and relations that exist between them being treated as the only subjects of meaningful language. Materialism in traditional formulations is vitiated, in Neurath's view, by its presenting mind as a function of matter, thus extending at least de facto recognition to the mental realm. Neurath rejected mind and mental states as irredeemably metaphysical, and he counselled against analyzing the meaning of 'matter' for reason of incipient 'subjectivitist tendencies.'14 One subjectivist tendency that became prominent in the writings of members of the Vienna Circle, which Neurath was particularly keen to see stamped out, was phenomenalism. An example is Carnap's Der Logische Aufbau der Well (1928) with its logistic programme for constituting intersubjective concepts of science out of elementary phenomenalist experiences, using the symbolic logic of Whitehead and Russell's Principia Mathematica. Neurath, whose view Carnap was later to adopt, argued to the contrary that use of a phenomenalist basis leads to idealist metaphysics. The inter-subjective statements of science, Neurath claimed, cannot have their meanings constituted from phenomenalist concepts whose supposed referents are private experiences, inaccessible in space and time. ${ }^{15}$

Physicalism and the doctrine of linguistic closure are fashioned by Neurath as intellectual weapons for class struggle. They enable socialists to expose the bourgeoisie's metaphysical and religious dogmas as anachronistic and meaningless cant. Physicalism is also crucial to the construction of unificd science - the nub of the new socialist culture - with which we shall deal below.

13Philipp Frank, Modern Science and Its Philosophy (Cambridge: Harvard UP, 1949), p. 17. Sce also Loren Graham, Science and Philosophy in the Soviet Union (New York: Knopf, 1972), p. 42ff.; and John T. Blackmore, Ernst Mach: His Work, Life, and Influence (Berkeley: California UP, 1972), p. 236 ff.

${ }^{11}$ Neurath, Empiricism , p. 359.

15 Nemeth, p. 104. 


\section{OTTO NEURATH}

\section{Neurath's Metascience}

Most studies of logical positivism depict it as revolving around the verification principle which, in the original published formulation given it by Frederick Waismann, locates the meaning of a cognitive or factually informative statement in its method of verification. Before any such statement can be tested, its meaning, the principle implies, must be ascertained by specifying under what circumstances it could be proven true. For the student of Neurath it is a fact of signal interest that he seldom mentions and never seriously avails himself of the verification principle. Instead of treating meaning as a function of verification or of any other method, he connects it to the (for him) only genuine subject matter, the space-time domain of physicalism. The physicalist language of science and common sense contains at any time the entire available corpus of meaningful statements.

It follows from the doctrine of physicalism that philosophy is a bogus discipline. Philosophical locutions are meaningless, being neither tautological transformations such as occur in mathematics and logic, nor physicalist statements. Nor, according to Neurath, is there any philosophical activity of conceptual elucidation in the way that Wittgenstein and Schlick imagined. Karl Menger records that 'In the early 1930s, after Carnap had gone to Prague, a controversy ... arose in the Circle when Waismann lechoing the latest thoughts of Wittgenstcin] proclaimed that one could not speak about language. 16 Neurath, with his brother-in-law Hans Hahn, took strong exception to this view. Neurath was adamant that the scientific language of physicalism can be used in reference to itself. ${ }^{17}$ Language itself is spatio-temporally situated as sounds and inscriptions on pages, so the study of language is within the compass of science.

Waismann, Schlick and others looked on phenomenalist (private experience) statements as verifiers or test-statements for scientific laws and theories. Neurath, in contrast, advocated protocol statements, which are shorn of subjective elements and use only physicalist terms.

Protocol statements are factual statements of the same linguistic form as other factual statements, but in them a personal name always occurs several times, in a definite connection with other terms. A complete

${ }^{16}$ Karl Menger, Logic and Mathematics, ed. Brian McCuinness (Dordrecht: Reidel, 1980), p. xii.

17Heiner Rutte, "Der Philosoph Otto Neurath," Arbeiterbildung in der Zwischenkriegszeit Otto Neurath, ed. Gerd Arntz (Wien/Munchen: Locker Verlag, 1982), p. 76. 
protocol statement might for example be worded like this: "Otto's protocol at 3:17 o'clock [Otto's speechthinking at 3:16 o'clock was (at 3:15 o'clock there was a table in the room perceived by Otto)]." 18

The parenthetic expression records Otto's initial experience, and that which is bracketed reports his subsequent private verbal response. Proper names are preferred to personal pronouns in order that the components of the protocol may be independently tested, e.g. by being found in the protocols of other observers. The protocols of different observers may conflict, and when this happens at least one of them is to be rejected.19

At this stage there is an equivocation to expose at the heart of Neurnth's metascience. A number of his remarks about protocols suggest a traditional empiricist model of appraisal in which concrete statements of observations or experimental results (protocol statements) confront individual laws or hypotheses. ${ }^{20}$ In this view, which predominated among members of the Vienna Circle and was embedded in their verifiability principle, test statements or protocols are privileged in deciding the fate of gencralizations. But Neurath's apparent endorsement of this model jars with his thesis of linguistic closure which, we recall, denies the possibility of comparing statements with 'reality' or experience. From this conjunction of doctrines, questions arise as to how protocol or test statements, as fallible records of experience, are themselves to be controlled or assessed by experience, and why they should be privileged in evaluating gencralizations. Neurath never seriously confronts these difficulties.

The second model of appraisal in Neurath's writings is holistic rather than atomic as above, and owes much to the French polymath Pierre Duhem whose influence not merely on Neurath but on the Vienna Circle as a whole would almost certainly repay closer examination than it has received to date. Philipp Frank has related how ideas of Duhem along with those of his compatriot Pioncare were assimilated as early as 1907 by himself, Neurath and Hans Hahn in discussions they had together of Abel Rcy's La Theorie de physique chez les physiciens contemporains (1907). 21 Ncurath was particularly impressed by Duhem's arguments for the inconclusiveness of scientific experiments. Affirming the holistic

18 Neurath, Papers , p. 93.

${ }^{19}$ R. W. Ashby, "Logical Positivism," A Critical History of Western Philosophy, ed. D. J. O'Connor (London: Free Press, 1964), p. 501.

20 Otto Neurath, "Prognosen und Terminologie in Physik, Biologie, Soziologic," Travaux Du IXe Congres Internationale De Philosophie (Paris, 1937), pp. 82-84.

${ }^{21}$ Frank, p. 3. 


\section{OTTO NEURATH}

character of scientific knowledge, Duhem himself described as follows what he took to be the practical upshot of that holism:

the physicist can never subject an isolated hypothesis to experimental test, but only a whole group of hypotheses; when the experiment is in disagreement with his predictions, what he learns is that at least one of the hypotheses constituting this group is unacceptable and ought to be modified; but the experiment does not designate which one should be changed. 22

A point that Neurath bases on this and which is severally repeated by him is that contradictions between experimental results and systems of hypotheses can always be removed through the addition of auxiliary hypotheses. Duhem agreed with Poincare that consistency between theories and experimental results is no indication of truth since an infinite number of theories may be imposed on any given set of observation reports. Experimental results, as Neurath puts it, are 'ambiguous', which is tantamount to what philosophers nowadays term the 'underdetermination' of theories by data.

Neurath's second model of scientific appraisal combines the ideas of Duhem with his own doctrine of linguistic closure. Protocol sentences in this model have no privileged role as test statements, and if they contradict hypotheses scientists are free to reject either. Statements are not appraised by objective empirical testing, being incomparable with experience or reality. Scientists are without this resource in deciding which statements are to be included in the corpus of current scientific knowledge. Whether intentionally or unwittingly, Neurath's account deprives science of empirical character by effectively denying constraints of experience. His only requirement is for scientists to eliminate contradictions between statements. Neurath to the contrary, there is more than a faint suggestion in this model of what might be termed a coherence theory of 'acceptance' of scientific statements. Perhaps his lack of frankness about 'coherence' owed to the coherence theory of truth having been a central part of the (for Neurath) philosophical anathema of absolute idealism. Be that as it may, of the existence of objective standards of truth and falsity Neurath became increasingly doubtful, recommending in later works that they be ignored altogether. The second of Neurath's models of appraisal come to coalesce with skepticism.

22Pierre Duhem, The Aim and Structure of Physical Theory, trans. Philip P. Wiener (New York: Atheneum, 1981), p. 187. 
One of the more enduringly interesting of Neurath's metascientific papers is a review of Karl Popper's Logik der Forschung (1934). 23 It presages by almost thirty years, motifs of Thomas Kuhn's The Structure of Scientific Revolutions (1962) which have the status nowadays of received dogmas. Among these anticipations are Neurath's advocacy of an historically informed, non-prescriptive metascience; his thesis that scientists are usually claborating rather than testing theoretical structures, and his denials of a final goal for scientific research and of rules to guide scientists' choices of protocols and gencralizations.

Abjuring the prescriptive mood of Popper's Logik der Forschung, which is manifested in its distinctive methodological rules, Neurath presents his metascience to account for the historical development of science. The unit of scientific research is not the discrete theory, as envisaged by Popper, but an 'encyclopedia' or loose structure of thcoretical and protocol statements, which foreshadows Kuhn's notion of 'paradigm' as the 'disciplinary matrix' or presuppositional framework within which a community practices 'normal science.' Encyclopedias, as depicted by Neurath, are not subjects for experimental tests but programmes with histories to which statements are added and removed to achicve consistency between theories and protocols.

Taking heed of Duhem's arguments against conclusive experimental appraisals of scientific theories or laws, and recognizing the complexity of actual research situations, Neurath rejects the suggestion of a monistic scientific method, which anticipates the method-pluralism discussed in Paul Feycrabend's polemic Against Method. The verificationism of his colleagues in the Vienna Circle and Popper's method of falsification are both dismissed by Neurath. An encyclopedia rarely agrees with all relevant protocols. Certain protocols will be consistent with predictions and others inconsistent, which relations Neurath respectively designates as 'confirmations' and 'shakings' (contradictions shake the confidence of scientists in encyclopedias). The decisions of scientists regarding research projects can never be determined by protocols. Some scientists may disregard 'shaking' protocols and continue developing an encyclopedia; others may scek to climinate contradictions with the aid of auxiliary hypotheses; yet others may reject a seemingly well supported encyclopedia in the belief that it obstructs further development in their branch of science. Science is substantially an extra-logical process in which decisions to accept or reject encyclopedias or their component statements have to be taken without recourse to general rules or criteria. Such theorists as Popper who fail to appreciate that scientists' decisions are inherently subjective and ad hoc are accused by Neurath of

${ }^{23}$ The paper is "Pseudorationalismus der Falsifikation" (1935), translated in Philosophical Papers as "Pscudorationalism of Falsification." 


\section{OTTO NEURATH}

'pseudorationalism.' As there exists no 'special theory of the importance .. . for the progress of science or life in general' of the various social and technical factors that influence their discriminations between specific statements and between encyclopedias, scientists are perforce their own touchstones. 24

In scientific change, Neurath sees both continuities and discontinuities. Acceptance or rejection of statements always occurs within an inherited corpus of knowledge, this being the point of his famous metaphor of cognitive boat repair. Scientists 'are like sailors who on the open sea must reconstruct their ship but are never able to start afresh from the bottom. ${ }^{25}$ Within this corpus, however, there are discontinuities in the ontologies of successive theories or encyclopedias even, Neurath suggests, when a new theory entails all its predecessor's predictions. What Neurath implacably opposes is the idea of finality in science, of successive scientific encyclopedias progressing towards an ultimate encyclopedia which is comprehensively informative and accurate. Such in essence was Popper's vision of the aim of science in Logic der Forschung.

\section{Sociology as Part of Unified Science.}

In the broadest of Neurath's several senses, 'unified science' signifies a programme for promoting physicalist language. The programme is directed at expunging theological and metaphysical expressions from natural languages (expressions which Neurath presented in an index verborum prohibitorum'), and at coordinating these languages with the language of science. Referring exclusively to space-time relations, purified languages would translate readily into one another. Neurath envisaged them as a 'universal jargon' 26 of physicalism, simplifying communication between cultures and advancing the cause of socialist internationalism. 27

${ }^{24}$ Neurath, Papers , p. 157; cf. p. 134. The ideal of social factors influencing scientists' deliberations and choices, which is suggested by Neurath on a number of occasions, bespeaks an embryonic sociology of science. This may have owed something to Mannheim whose Ideologie und Utopie Neurath reviewed in 1930.

25 Neurath, Empiricism, p. 199.

2626. Otto Neurath, "Foundations of the Social Sciences" in Foundations of the Unity of Science, vol. 2, eds. Otto Neurath, Rudolf Carnap, Charles Morris (Chicago: Chicago UP, 1970), p. 6.

27 Nemeth 109. Another instrument for international communication to which Neurath devoted a good deal of attention was an 'isotype' picture language, inspired by Egyptian hieroglyphics. See his monograph Modern 
In a more restrictive sense, 'unified science' marks a project for reforming the 'encyclopedia' comprising all currently accepted scientific statements. 28 The goal ascribed by Neurath to this project is piecemeal filling of gaps, and elimination of ambiguities and contradictions between statements so that laws of different disciplines can be brought together to improve the accuracy and range of scientific predictions. Accurate concretc predictions cannot be achicved within any one scientific discipline. To predict, for example, the course of a fire would require chemical, metcorological, sociological, physical laws ctc., which 'must be conccived as parts of a system ... of unified science. 29 'System' is apt to mislcad in this context, suggesting that Neurath urges the integration of science into one deductive hierarchy of statements. This, for him, would be impossible; the corpus of scientific statements is permanently in flux, the upshot being that unified science is restricted to particular deductive orderings.

In his discussions of unified science, in the sense just distinguished, Neurath's attention is mainly focused on social science, though he sces no material difference between the subject-matters or methods of social and physical sciences. The suggestion of Dilthey and his followers that Das Verstehen is distinctive of human studies receives from Neurath the tart reply that it (empathy) 'may help the research worker' but enters 'the totality of scientific statements as little as does a good cup of coffee which also furthers a scholar in his work. 30 Social scientists are required by Neurath to use only physicalist statements and in psychology, specifically, mentalistic terms (designating thoughts, feelings, wants, motives etc.) that cannot be translated into words referring to bodily processes must be excluded from unified science.

Having earlicr shown that Marxism permeates Neurath's perspective on history and that he views his theory of knowledge as a contribution to socialist culture, it remains to complete the circle of his thought by examining how he justifies Marxism as a component of unified science. Neurath's most important work on sociology is the monograph, Empirische Soziologie, that appeared in 1931. The study rests on a physicalist social ontology: 'One can make no mistake', Neurath assures, if one speaks everywhere of precisely specifiable spatio-temporal objects

Man in the Making (New York: Knopf, 1939).

28 The term encyclopedia is also used by Neurath as a proper noun in the collective title of a projected twenty six volume International Encyclopedia of Unified Science (to be accompanied by a ten volume Visual Thesaurus), only two volumes of which have so far seen the light of day.

${ }^{29}$ Neurath, Papers , p. 59.

${ }^{30}$ Neurath, Empiricism , p. 357. 


\section{OTTO NEURATH}

(. . . of the state as an aggregate of men, streets, houses, prisons . . .).31 Methodological individualism would seem a natural concomitant for this ontology, yet statements comprising collective concepts (peoples, tribes, classes and the like) are freely used by Neurath, with no suggestion of their having to be reduced to statements about concrete or typical individuals. Prediction, the paramount aim of physicalist sociology, relies on laws of statistical frequencies, most of which are relative to particular social periods. The proper subjects of social scientific predictions are social groups (structures of individuals), which are seen as having greater stability or regularity than single individuals. Physicalist sociology is broadly behaviourist, with social groups being individuated by distinctive customs and by close stimulus-response between their members.

The course of human life is treated no differently by a strictly scientific sociology than ... life in an ants' nest or in a bee-hive. We investigate the influence of such course of events on the living standard, on the conditions of pleasure and displeasure of the participants, where pleasure and displeasure are consistently defined by observable behaviour. 32

The discipline of sociology Neurath sees as having emerged last century from history and political economy. Marx and Engels effectively synthesized these disciplines by tracing social change to economic factors and effectively showing that socialism can be predicted from socialeconomic developments. The materialist conception of history is physicalist and therefore part of unified science. 'Of all the attempts at creating a strictly scientific unmetaphysical physicalist sociology, Marxism is the most complete. 33

Marxism qua scientific theory of society simultancously provides a spur to and strategy for social change. The use of Marxism by the Soviet state for social engineering in the 1920s and 30s exemplifies, for Neurath, its role as technology for constructing socialism. In capitalist societies of the West, in turn, he regards Marxism as a source of solidarity and inspiration for the revolutionary proletariat. This class is animated by Marxism's forecast of the capitalist market economy being replaced by a wholly planned administrative economy in which the technology and large-scale institutions of capitalism will be used to create a classless, equitable society. More ambitiously still, Neurath looks forward to a

${ }^{31}$ Neurath, Empiricism, p. 352.

32 Neurath, Papers , p. 45.

${ }^{33}$ Neurath, Empiricism , p. 349; also Otto Neurath, "Burgerlicher Marxismus," Der Kampf 23 (1930): 227-232. 
classless world socialist state, managed according to a single international cconomic plan.

One cannot help but be struck by Neurath's using Marxism as if it were an empirically privileged system whose predictions of the decline of capitalism and of the emergence and character of socialism were beyond doubt. Yet nothing in his abstract analysis of the status of social scientific prediction justifies such surety. 'Sometimes a change in a sociological situation may be predictable though the direction of the change cannot be known. . . . But this happens in physics too: a cone spinning on its point will fall, but which way, cannot be predicted. 34 Long-range accuracy is disturbed by intrinsic novelty or periodization in social development. Factual laws or uniformities of social life are relative to specific social structures, and as concepts concerning different types of economic and social conditions presuppose at least some acquaintance with those conditions, concepts are often available for formulating predictions. Another of Neurath's arguments suggests that the idea of predicting knowledge is paradoxical 35 for, were it predictable, knowledge would be available in the premises of the predictive inference. These arguments sabotage rather than support Neurath's dogmatic confidence in Marx's social forecasts.

Close examination of Neurath's account of social science reveals an equivocation regarding relations between social change and sociological predictions of it. The nub of the matter is this: when sociologists succeed in predicting an event or development, has the development occurred despitc or because of their predictions? Are sociological predictions causes (or part-causes) of social processes, exerting a sclf-fulfilling effect and, if so, are they deliberately conceived with this in mind? Both views of prediction are suggested in Neurath's writings. The didactic one, that social prediction concerns events that occur independently of it, is intimated when Neurath says that Marxism

can describe the whole structure of an age as a historical formation with special laws conditioned by the situation of the time (each social order has e.g. its own laws of population). The derivation of a distribution of living standards from existing conditions leads to a deduction of a social order from the old. 36

${ }^{34}$ Neurath, Empiricism, p. 362.

35There is surcly irony in the fact that Popper, a thinker as hostile to Marxism as Ncurath is approving, presents materially the same argument in the preface of his The Poverty of Historicism. There is nothing to say, however, that Popper obtained his argument from Neurath.

36 Ncurath, Empiricism, p. 358-359. 


\section{OTTO NEURATH}

Elsewhere, however, Neurath argues that predictions ineluctably influence social development, and should be consciously so used. He suggests that social change obeys no independent laws and that predictions of Marxism are instruments for galvanizing the proletariat. Common 'planned action' he remarks 'is possible only if the participants make common predictions.' He states that 'Pseudo-rationalism is inclined to treat everything as calculable, whereas strict science comes to admit the multiple interpretations of its systems, and to leave the unitary character of life to other factors, above all to common agreement on decisions. ${ }^{.37} \mathrm{Be}$ this as it may, one cannot help noticing Neurath's convenient omission of complicating factors, there being no discussion for example of selfdefeating predictions such as Marxism's predictions forewarning class enemies and strengthening opposition to the proletariat.

This problem of assigning conflicting roles to prediction is obviously not inherent in Marxism, as can be seen from the works of Louis Althusser, For Marx and Reading Capital. According to him, Marx's philosophy (in particular, what commentators distinguish as dialectical materialism) envisages knowledge as practice taking place within thought; Marx presents the theory of theoretical practice. Practice in each science, while devoted to secking knowledge of real objects, remains unavoidably confined to working on and transforming theoretical objects. The validity of products of theoretical practice is decided in terms of, not external reality but, standards internal to science, and the development of each science, in parallel fashion, is internally driven, without regard to social exigencies. One can imagine that this position would have been broadly congenial to Neurath, certain of whose own views (theories as programmatic structures; reality screened off by theory; underdetermination of theory by 'facts') can be seen as partial presagements. But, and this is crucial, in Althusser's interpretation of Marx, Neurath's problem of whether to interpret social scientific predictions litcrally or pragmatically simply does not arise. Theoretical practice proceeds independently of, and untested in terms of, external reality.

37 Neurath, Empiricism , p. 407. 